\title{
Acanthosis Nigricans in a Patient with Lung Cancer: A Case Report
}

\author{
Duru Serap, ${ }^{1}$ Sever Özlem, ${ }^{1}$ Yüceege Melike, ${ }^{1}$ Dilli Alper, ${ }^{2}$ Albayrak Aynur, ${ }^{3}$ \\ Arıkök Ata Türker, ${ }^{3}$ and Sadik Ardıç ${ }^{1}$ \\ ${ }^{1}$ Dışkapı Yıldırım Bayazıt Education and Reserch Hospital, Chest Diseases Clinic, 06200 Ankara, Turkey \\ ${ }^{2}$ Dışkapı Yıldırım Bayazıt Education and Reserch Hospital, Radiology, 06200 Ankara, Turkey \\ ${ }^{3}$ Dışkapı Yıldırım Bayazıt Education and Reserch Hospital, 2nd Pathology Clinic, 06200 Ankara, Turkey
}

Correspondence should be addressed to Duru Serap, akcalis@hotmail.com

Received 5 May 2010; Accepted 30 June 2010

Academic Editor: Aminah Jatoi

Copyright (C) 2010 Duru Serap et al. This is an open access article distributed under the Creative Commons Attribution License, which permits unrestricted use, distribution, and reproduction in any medium, provided the original work is properly cited.

\begin{abstract}
Some skin lesions may accompany malignancies. Acanthosis nigricans, one such lesion, is a paraneoplastic dermatosis characterized by hyperpigmented and velvety verrucose plaques observed as symetric eruptions. With this report, we aim to present a rare case of concomitant lung cancer and acanthosis nigricans. Malignant acanthosis nigricans is most commonly associated with intra-abdominal malignancies. A 65-year-old patient who had hyperpigmented, hypertrophic and symmetric verrucose lesions at the flexor surfaces of the lower and upper extremities, face, palms and the axillary region. Thoracic computed tomography demonstrated a hypodense mass lesion with a dimension of $5 \times 5.5 \mathrm{~cm}$ at the center of basal segment bronchi of the left pulmonary lobe. Fiberoptic bronchoscopy showed that the access to the lower left lobe was almost completely obstructed by the endobronchial lesion. The result of the histopathologic examination of the endobronchial tissue biopsy was reported as non-small cell (adenocarcinoma) lung cancer. Result of the histopathologic analysis of the punch biopsy of the skin lesions was reported as acanthosis nigricans. There are no pathognomonic dermatological findings for lung cancer. In conclusion, there are skin lesions that accompany lung cancer and we believe that these should be considered for differential diagnosis.
\end{abstract}

\section{Introduction}

Some skin lesions may accompany malignancies. Acanthosis nigricans, one such lesion, is a paraneoplastic dermatosis characterized by hyperpigmented and velvety verrucose plaques observed as symmetric eruptions.

It is often localized on flexor surfaces such as the axilla, posterior neck fold, anterior umbilical, and popliteal and inguinal areas where skin folds. It may be idiopathic but may also be associated with endocrinal disorders, malignancies, medicines, and genetic syndromes. Besides, acanthosis nigricans may also present autosomal dominant involvement [13].

Malignant acanthosis nigricans is most commonly associated with intra-abdominal malignancies. There are very few reports in the literature of malignant acanthosis nigricans associated with lung cancer.

With this report, we aim to present a rare case of concomitant lung cancer and acanthosis nigricans.

\section{Case Presentation}

A 65-year-old male patient who presented to our clinic had the complaints of cough and phlegm for the past 10 years which particularly exacerbated in winter and shortness of breath exacerbating with effort for the past one year. An informed consent was taken from the patient. Patient had no comorbid disease including diabetes mellitus.

The patient also had dark-colored lesions that he first observed one month ago and spread to the body thereafter, and the additional complaints of worsened shortness of breath and weight loss. His history involved smoking, 60 boxes/year. His familial history had no relevant findings. Physical examination revealed the following values: BP: $120 / 80 \mathrm{mmHg}$, RR: $16 / \mathrm{min}$, and temperature $36.5^{\circ} \mathrm{C}$. The patient had body weight: $64 \mathrm{~kg}$ and body length: $170 \mathrm{~cm}$, BMI: $22.14 \mathrm{~kg} / \mathrm{m}^{2}$.

The patient had hyperpigmented, hypertrophic and symmetric verrucose lesions at the flexor surfaces of the lower 


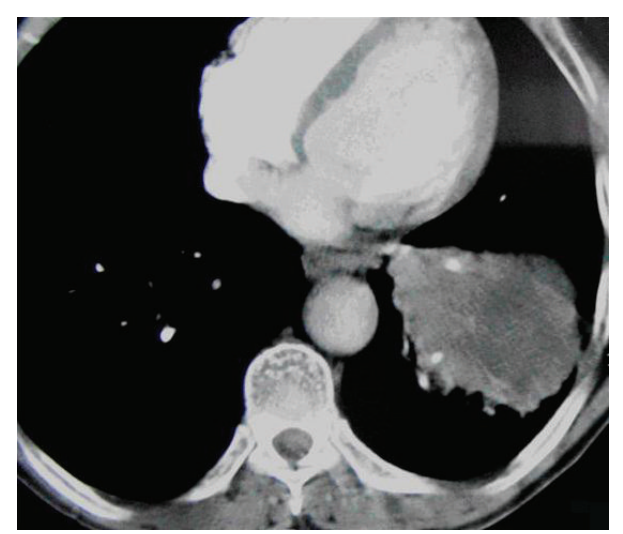

Figure 1: Thoracic computed tomography (a hypodense mass lesion at the left pulmonary lobe).

and upper extremities, face, palms, and the axillary region. An examination of the respiratory tract with auscultation revealed bilateral infrequent expiratory rhoncus. Findings of other examinations were normal. Laboratory findings showed an ESR value of $64 \mathrm{~m} / \mathrm{h}$, fasting blood glucose as $74 \mathrm{mg} / \mathrm{dl}$. Compensated respiratory acidosis was observed during blood gas analysis. Other laboratory findings were within normal ranges.

Thoracic computed tomography demonstrated a hypodense mass lesion with a dimension of $5 \times 5.5 \mathrm{~cm}$ at the center of basal segment bronchi of the left pulmonary lobe, which did not have clear borders distinguishable from the peripheral consolidation region (Figure 1).

Fiberoptic bronchoscopy showed that the access to the lower left lobe was almost completely obstructed by the endobronchial lesion.

Abdominal tomography, esophagoduodenoscopic, colonoscopic examination revealed no malignancies, only erosive gastritis was found. Primary lesion was considered as the primary tumor as there was no malignancy at any organ. The result of the histopathologic examination of the endobronchial tissue biopsy was reported as nonsmall cell (adenocarcinoma) lung cancer (Figure 3).

Result of the histopathologic analysis of the punch biopsy of the skin lesions was reported as acanthosis nigricans (Figure 4).

\section{Discussion}

There are no pathognomonic dermatological findings for lung cancer. However, some skin lesions should suggest lung cancer in differential diagnosis. Acanthosis nigricans is one such lesion. Acanthosis nigricans may both be benign or malign. Its benign form may be observed in association with some endocrinal disorders, obesity, some genetic syndromes, and drug use (nicotinic acid, estrogen, corticosteroids) [4, 5]. We could not manage to find the actual percentage for "idiopathic acanthosis nigricans" from the literatures, but we consider that the most of the cases can be associated with a disease.

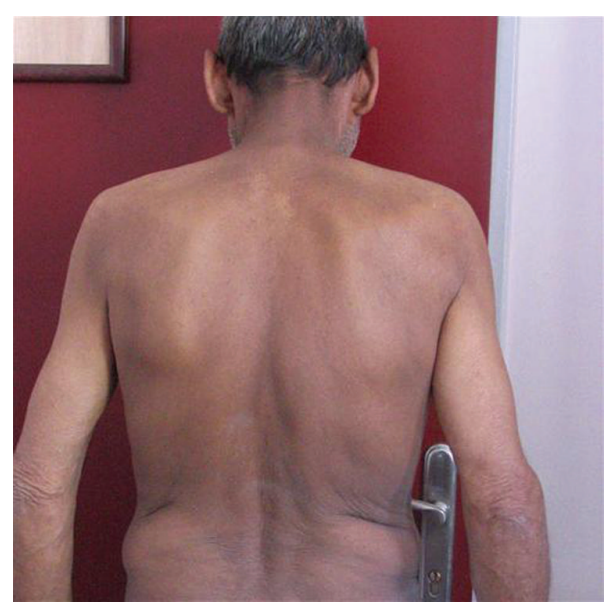

(a)

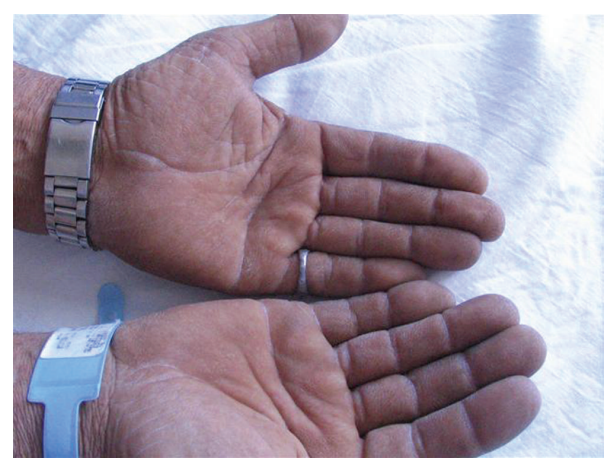

(b)

Figure 2: Hyperpigmentation in the back and hands.

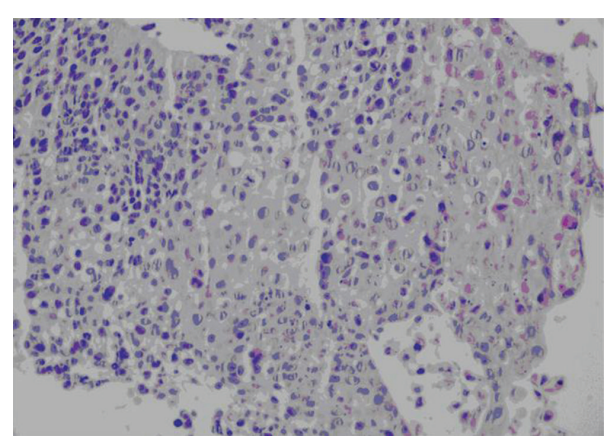

Figure 3: Coarse hyperchromatic atypical cell cluster with an average-width eosinophilic cytoplasm with evident nucleolus (H\&E, x40 obj).

Malign acanthosis nigricans accounts for $20 \%$ of all acanthosis nigricans cases. It develops as a result of expression of the transforming growth factor alpha (TGF alpha) of tumor cells, melanocyte stimulating hormone alpha, and peptides causing cellular proliferation including insulin-like growth factor $1[6]$.

Of the malignancies accompanying malign acanthosis nigricans in the adult population, $45-69 \%$ are gastric adenocarcinomas. Malign acanthosis nigricans is observed with a frequency of $70-92 \%$ of all abdominal neoplasms [7-9]. 


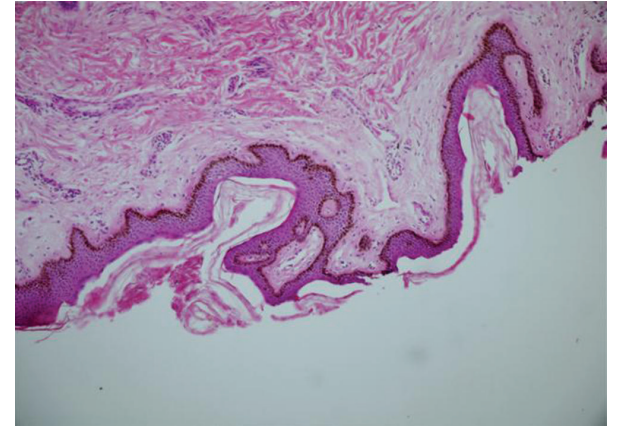

FIgURE 4: Hyperkeratosis, papillomatous mild acanthosis in the epidermis and hyperpigmentation at the basal layer (H\& E, x20 obj).

approximately, 9\% of all MAN cases are related with extraabdominal malignancies: Endometrium [10] lymphoma [11], mycosis fungoides, melanoma, and sarcomas [12]. These are all presented as case reports.

After diagnosing as acanthosis nigricans, benign diseases were investigated (no diabetes, obesity, drug use such as nicotinic acid, estrogen, or corticosteroid). After that, possibility malign disease was thougt. The most common form of malignancy with MAN, the abdominal malignancy was investigated by abdominal tomography, esophagoduodenoscopy, colonoscopy, and rectoscopy which were all normal. The edoscopic investigations should be done in every patient with MAN. They all revealed normal findings in this patient. Brain computerised tomography and bone scintigraphy revealed no lesions. If there were no lung cancer in our case, the other rare malignancies with MAN listed above would have been searched.

First described by Pollitzer in 1891, acanthosis nigricans is a key indicator of insulin resistance independent from the body mass index [13-15]. It has an increasing incidence in obese children and adults. It may be seen together with other skin disorders in patients with insulin resistance and uncontrolled diabetes $[16,17]$. The patient had no diabetic disease.

Co-occurrence of acanthosis nigricans and lung cancers is rare. The association with bronchial carcinoma was first reported in 1909 [18]. Curth et al. [19] extensively reviewed the association of pulmonary neoplasms and acanthosis nigricans. To date, eight cases of adenocarcinoma of the lung and five cases of squamous carcinoma of the lung have been reported in association with acanthosis nigricans [20]. A patient with bronchoalveoler carsinom is reported [21]. And only few cases with pulmonary malignancy with acanthosis nigricans are reported in the literature [22, 23]. It alone may predict malignancy or may develop with other signs or occur later. Tumors are often in the advanced phase even when malign acanthosis nigricans is diagnosed simultaneously with the tumor. Since the patient had no radiography at the early phase and his recent radiography showed a large mass in the lung, we believe that the skin lesions developed later. Treatment of malign acanthosis nigricans depends on the treatment of the underlying malignancy. Skin lesions usually regress as treatment success is achieved.

No masses were detected during the scans of the other organs. Being assessed as advanced phase nonsmall cell lung cancer, the patient was examined by the oncology department. Chemotherapy and radiotherapy were initiated and regressions were noted in the patient's skin lesions, consistent with the literature. The patient refused to go through thorasic surgery and died three months after presentation due to respiratory failure.

In conclusion, there are skin lesions that accompany lung cancer and we believe that these should be considered for differential diagnosis.

\section{References}

[1] R. A. Schwartz, "Acanthosis nigricans," Journal of the American Academy of Dermatology, vol. 31, no. 1, pp. 1-22, 1994.

[2] S. Kang and A. J. Sober, "Disturbances of melanin pigmentation," in Dermatology, S. L. Moschella and H. J. Hurley, Eds., pp. 1442-1474, WB. Sauders, Philadelphia, Pa, USA, 3rd edition, 1992.

[3] R. R. Maldonado, "Diseases of pigment change," in Textbook of Pediatric Dermatology, R. R. Maldonado, L. C. Parish, and J. M. Beare, Eds., pp. 243-267, Grune \& Stratton, Philedelphia, Pa, USA, 1st edition, 1989.

[4] T. M. Mekhail and M. Markman, "Acanthosis nigricans with endometrial carcinoma: case report and review of the literature," Gynecologic Oncology, vol. 84, no. 2, pp. 332-334, 2002.

[5] G. Karakayalı, M. Koçak, B. Pençe, and A. Pınar, "Malign akantozis nigrikans," Journal of Dermatology, vol. 3, pp. 36-37, 1993.

[6] M. Krawczyk, J. Mykała-Cieśla, and A. Kołodziej-Jaskuła, "Acanthosis nigricans as a paraneoplastic syndrome: case reports and review of literature," Polskie Archiwum Medycyny Wewnetrznej, vol. 119, no. 3, pp. 180-183, 2009.

[7] J. S. M. Yeh, S. E. Munn, T. A. Plunkett, P. G. Harper, D. J. Hopster, and A. W. Du Vivier, "Coexistence of acanthosis nigricans and the sign of Leser-trelat in a patient with gastric adenocarcinoma: a case report and literature review," Journal of the American Academy of Dermatology, vol. 42, no. 2, pp. 357-362, 2000.

[8] S. Sabir, W. D. James, and L. M. Schuchter, "Cutaneous manifestations of cancer," Current Opinion in Oncology, vol. 11, no. 2, pp. 139-144, 1999.

[9] S. Boyce and J. Harper, "Paraneoplastic dermatoses," Dermatologic Clinics, vol. 20, no. 3, pp. 523-532, 2002.

[10] S. J. Longshore, J. S. Taylor, A. Kennedy, and S. Nurko, "Malignant acanthosis nigricans and endometrioid adenocarcinoma of the parametrium: the search for malignancy," Journal of the American Academy of Dermatology, vol. 49, no. 3, pp. 541-543, 2003.

[11] M. Janier, C. Blanchet-Bardon, D. Bonvalet, M. Lenoble, F. Boiget, and J. Civatte, "Malignant acanthosis nigricans associated with non-Hodgkin's lymphoma. Report of 2 cases," Dermatologica, vol. 176, no. 3, pp. 133-137, 1988.

[12] K. T. Schmidt, M. C. Massa, and S. E. Welykyj, "Acanthosis nigricans and a rectal carcinoid," Journal of the American Academy of Dermatology, vol. 25, no. 2, pp. 361-365, 1991. 
[13] S. Pollitzer, "Acanthosis nigricans," in Internal Atlas of Rare Skin Diseases, P. G. Unna, M. Morris, and E. Besnier, Eds., pp. 1-3, HK Lewis \& Co, London, UK, 1891.

[14] H. A. Kobaissi, M. J. Weigensberg, G. D.C. Ball, M. L. Cruz, G. Q. Shaibi, and M. I. Goran, "Relation between acanthosis nigricans and insulin sensitivity in overweight Hispanic children at risk for type 2 diabetes," Diabetes Care, vol. 27, no. 6, pp. 1412-1416, 2004.

[15] M. L. Stoddart, K. S. Blevins, E. T. Lee, W. Wang, and P. R. Blackett, "Association of acanthosis nigricans with hyperinsulinemia compared with other selected risk factors for type 2 diabetes in Cherokee Indians: the Cherokee diabetes study," Diabetes Care, vol. 25, no. 6, pp. 1009-1014, 2002.

[16] S. Lamba, A. Krishtul, M.-H. Tan, and M. G. Lebwohl, "Acanthosis nigricans in a plaque of scleredema on the back of a diabetic patient: a case report," International Journal of Dermatology, vol. 44, no. 1, pp. 45-47, 2005.

[17] Y. Saray, D. Özcan, and D. Seçkin, "Skin findings in patients with type II diabetes mellitus," Turkiye Klinikleri Journal of Medical Sciences, vol. 25, no. 3, pp. 377-382, 2005.

[18] P. Galatz, "Contribution a l'etude clinique et histopathologique de la dystrophie pappillaire et pigmentaire (acanthosis nigricans) associe a un cancer pulmonaire," Annales de Dermatologie et de Syphiligraphie, vol. 5, pp. 321-343, 1914.

[19] H. O. Curth, A. W. Hilberg, and G. F. Machacek, "The site and histology of the cancer associated with malignant acanthosis nigricans," Cancer, vol. 15, pp. 364-382, 1962.

[20] D. S. Rigel and M. I. Jacobs, "Malignant acanthosis nigricans: a review," Journal of Dermatologic Surgery and Oncology, vol. 6, no. 11, pp. 923-927, 1980.

[21] D. G. Menzies, J. Choo-Kang, P. K. Buxton, and I. W. Campbell, "Acanthosis nigricans associated with alveolar cell carcinoma," Thorax, vol. 43, no. 5, pp. 414-415, 1988.

[22] N. Yoshino, S. Yamagishi, H. Kubokura et al., "Mediastinal lymph node metastasis of lung cancer with an unknown primary lesion having concurrent endocrine abnormality and acanthosis nigricans: report of a case," Annals of Thoracic and Cardiovascular Surgery, vol. 15, no. 6, pp. 397-400, 2009.

[23] K. Katsura, K. Sugiyama, H. Kitamura et al., "A case of squamous cell carcinoma of the lung associated with acanthosis nigricans and solitary bronchial papilloma," Japanese Journal of Thoracic Diseases, vol. 30, no. 11, pp. 1991-1995, 1992. 


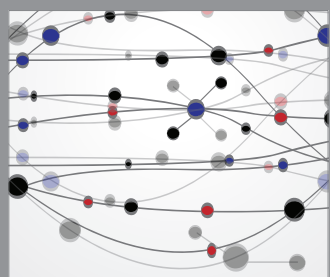

The Scientific World Journal
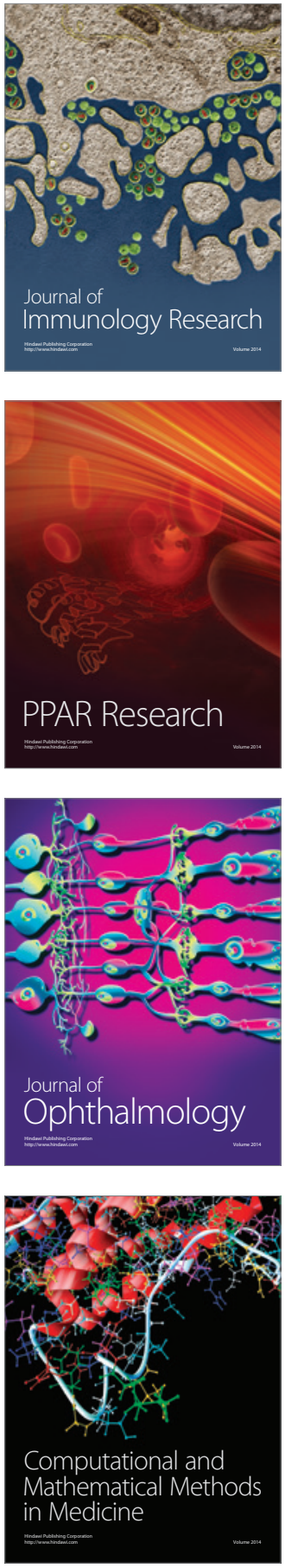

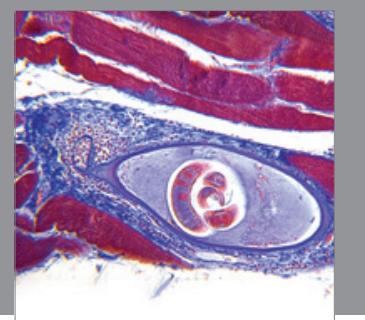

Gastroenterology

Research and Practice
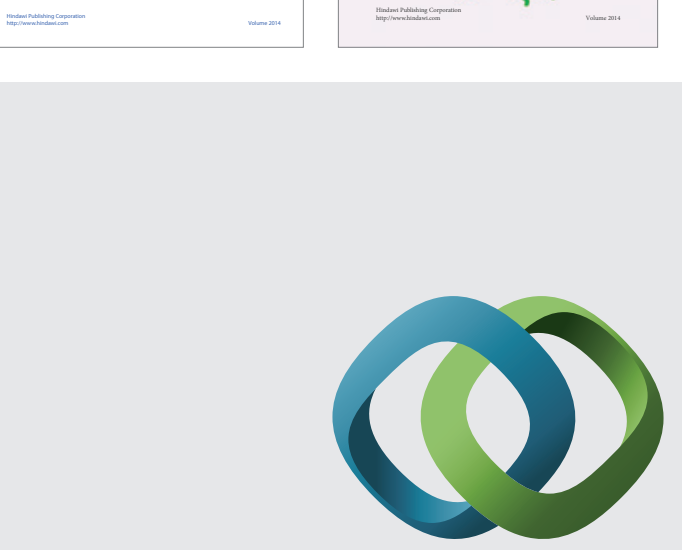

\section{Hindawi}

Submit your manuscripts at

http://www.hindawi.com
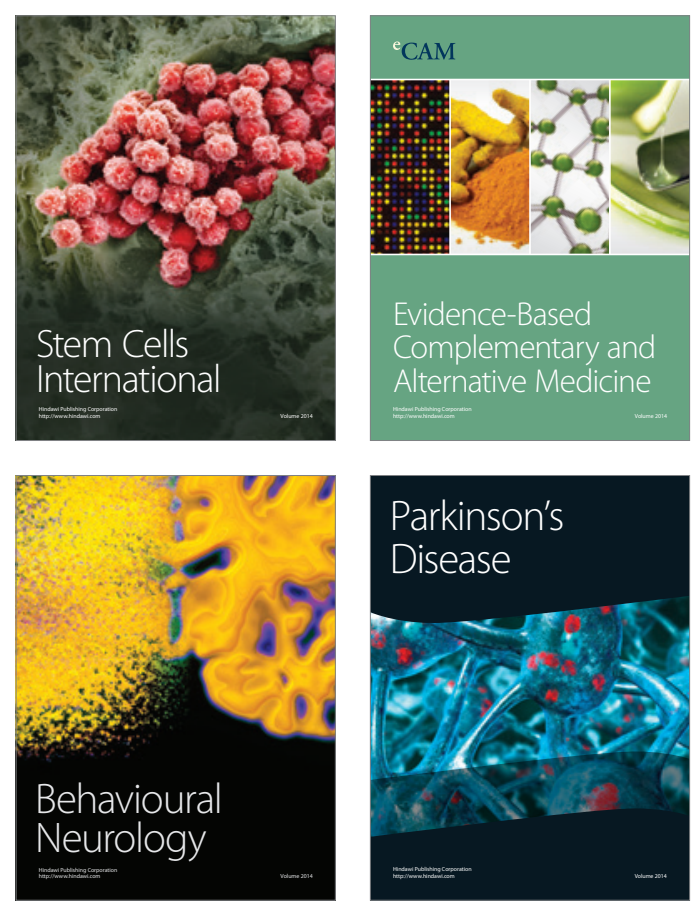

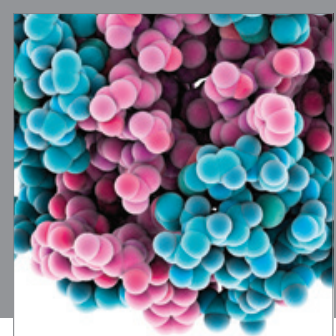

Journal of
Diabetes Research

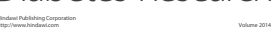

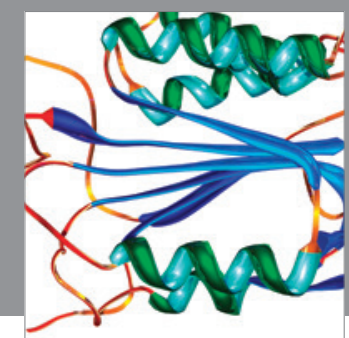

Disease Markers
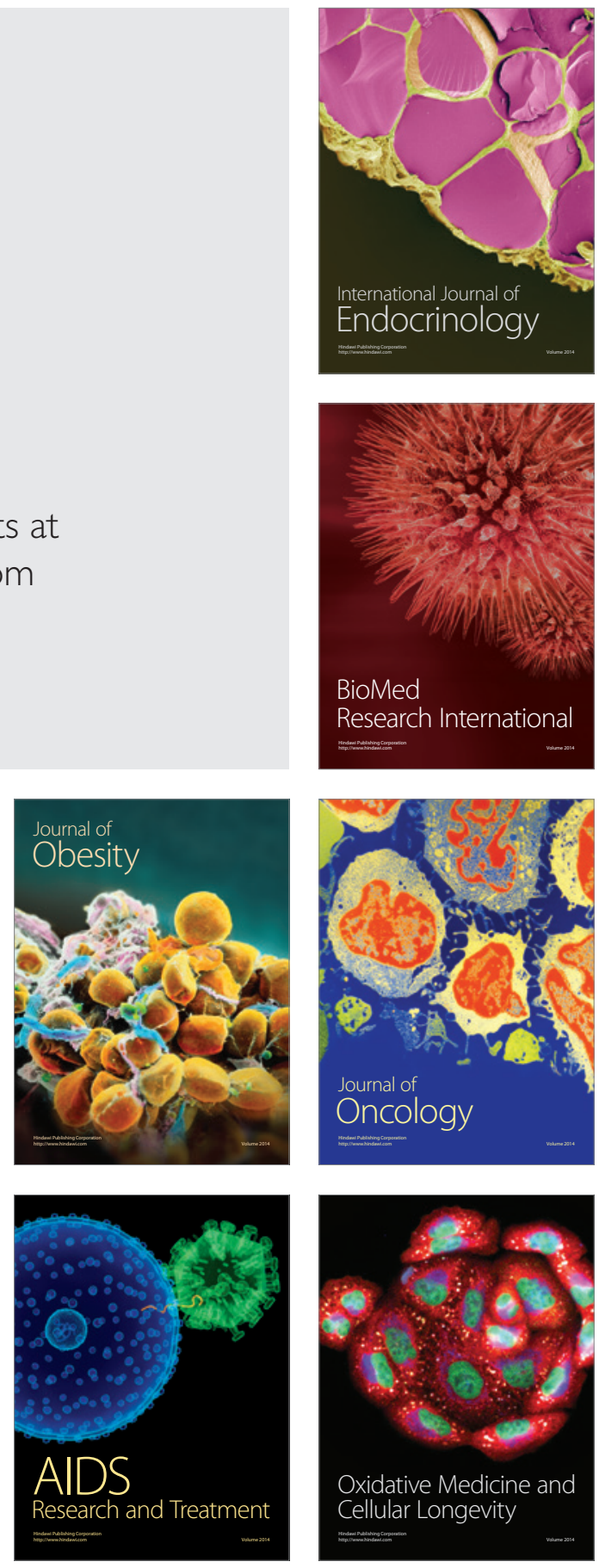